\title{
Microwave-Assisted Heating of Electrospun SiC Fiber Mats
}

\author{
Khos-Erdene Khishigbayar, Young Jun Joo, and Kwang Youn Cho ${ }^{\dagger}$ \\ Ceramic Fiber and Composite Center, Korea Institute of Ceramic Engineering and Technology, Jinju 52851, Korea
}

(Received July 20, 2017; Revised September 25, 2017; Accepted September 27, 2017)

\begin{abstract}
Flexible silicon carbide fibrous mats were fabricated by a combination of electrospinning and a polymer-derived ceramics route. Polycarbosilane was used as a solute with various solvent mixtures, such as toluene and dimethylformamide. The electrospun PCS fibrous mats were cured under a halogen vapor atmosphere and heat treated at $1300^{\circ} \mathrm{C}$. The structure, fiber morphology, thermal behavior, and crystallization of the fabricated $\mathrm{SiC}$ fibrous mats were analyzed via scanning electron microscopy (SEM), X-ray diffraction (XRD), and thermal imaging. The prepared SiC fibrous mats were composed of randomly distributed fibers approximately $3 \mu \mathrm{m}$ in diameter. The heat radiation of the $\mathrm{SiC}$ fiber mats reached $1600^{\circ} \mathrm{C}$ under microwave radiation at a frequency of $2.45 \mathrm{GHz}$.
\end{abstract}

Key words : Microwave, Electrospinning, Silicon carbide mat, Polycarbosilane, Heat radiation

\section{Introduction}

S ilicon carbide materials, especially in the form of fibers are attractive due to their high-temperature strength, high-frequency electronic property, and optoelectronic property. ${ }^{1,2)}$ One advantage of $\mathrm{SiC}$ fibers is the electromagnetic wave absorption properties of the fiber structure. In recent years, SiC fibers have been studied for application as interior/armor materials of stealth aircraft due their electromagnetic wave absorption properties. Zengyong Chu et al. studied the absorption properties of SiC fibers under microwave radiation, and they determined that better microwave absorbing performance could be achieved by changing the orientation of short fibers along with the thickness of the fiber sheet.3) Also, SiC fibers may be suitable for heater applications due to their dielectric permittivity and semiconducting properties. In particular, SiC fibers show ultrafast heating under microwave radiation because of their low weight and good heat conductivity. ${ }^{4}$

Conventional electric resistance heating techniques require a long time to heat a whole object due to heat transference from the surface to the interior of the object by thermal conduction. However, microwave heating techniques have a fast heating rate because microwaves can permeate $\mathrm{SiC}$ heating elements located in both the interior and exterior simultaneously. ${ }^{5}$ ) Microwave heating of $\mathrm{SiC}$ occurs by vibration of polarity and joule heating of eddy currents, which can be generated under electromagnetic microwave radiation. SiC fibers are fabricated with a small diameter to enable the extremely rapid conversion of an applied high-

\footnotetext{
${ }^{\top}$ Corresponding author: Kwang Youn Cho

E-mail : kycho@kicet.re.kr

Tel : +82-55-792-2710 Fax : +82-55-790-2530
}

frequency electromagnetic field. In addition, joule heating can occur due to the formation of conducting paths of $\mathrm{SiC}$ fiber under the influence of the applied field. SiC fibers react to microwave irradiation in different ways depending on their fabrication conditions. The influence of these conditions on microwave heating behavior have been analyzed by observation of the electric field distribution in a microwave oven, which revealed that $\mathrm{SiC}$ fiber mats can be heated by microwave radiation at a frequency of $2.45 \mathrm{GHz}{ }^{6}$ )

In this study, SiC fiber mats were prepared by an electrospinning method that can produce SiC fiber with a small diameter to increase heat radiation efficiency. We previously reported the heat radiation properties of comparatively large-diameter melt-spun $\mathrm{SiC}$ fiber under microwave irradiation. ${ }^{6}$ Based on those studies, the small-diameter electro-spun $\mathrm{SiC}$ fiber mats showed better heat radiation efficiency than large-diameter melt-spun fibers. Also, dense and random network $\mathrm{SiC}$ fiber mats can be prepared directly by the electrospinning method, unlike the meltspinning method which would require some extra procedures to prepare $\mathrm{SiC}$ fiber mats.

During the electrospinning process, various spinning parameters, such as solution concentration, electric potential, and flow rates, were applied in this experiment. The electrospun PCS fibrous mats were cured under a halogen vapor atmosphere and heat treated at $1300^{\circ} \mathrm{C}$ in $\mathrm{Ar}$ gas. The obtained $\mathrm{SiC}$ fibrous mats consisted of randomly distributed fibers approximately $3 \mu \mathrm{m}$ in diameter. The PCS fiber curing was performed with a 1:1 ratio of sample to iodine under low pressure, and results were summarized and compared with those of other methods. ${ }^{67)}$ Also, the heat radiation behavior of the $\mathrm{SiC}$ fiber mats was evaluated in terms of their morphology and crystallization under microwave radiation by infrared thermal imaging. 


\section{Experimental Procedure}

\subsection{Raw materials}

Commercially available polycarbosilane (TBMTech Co. Ltd., Korea) was used as a precursor for fabrication of $\mathrm{SiC}$ fiber. Several physicochemical properties of the PCS precursor are summarized in Table 1. Table 1 shows some basic characteristics of the polycarbosilane (TBMTech) precursors, such as their molecular weight as well as softening and melting temperatures. The average molecular weight $(\mathrm{Mw})$ and polydispersity $(\mathrm{Mw} / \mathrm{Mn})$ were 3053 and 2.42, respectively.

\subsection{Fabrication of SiC fiber}

Flexible silicon carbide fibrous sheets were fabricated by a combination of electrospinning and a polymer-derived ceramics route. Electrospinning is a fiber production method which uses electric force to draw charged threads of polymer solutions (Fig. 1). ${ }^{89}$ ) The process does not require the use of coagulation chemistry or high temperatures to produce solid threads from solution. This makes the process particularly suited to the production of fibers using large and complex molecules. ${ }^{10,11)}$ Oxide-based ceramic fibers, such as $\mathrm{Al}_{2} \mathrm{O}_{3}$, $\mathrm{SiO}_{2}, \mathrm{TiO}_{2}$, and $\mathrm{ZnO}$ fibers, have been fabricated by electrospinning corresponding sol-gel solutions; however, nowadays other ceramic fibers are fabricated by this method. ${ }^{12-14)}$

In this work, polycarbosilane (PCS) was used as a solute with various types of solvent mixtures, such as toluene and

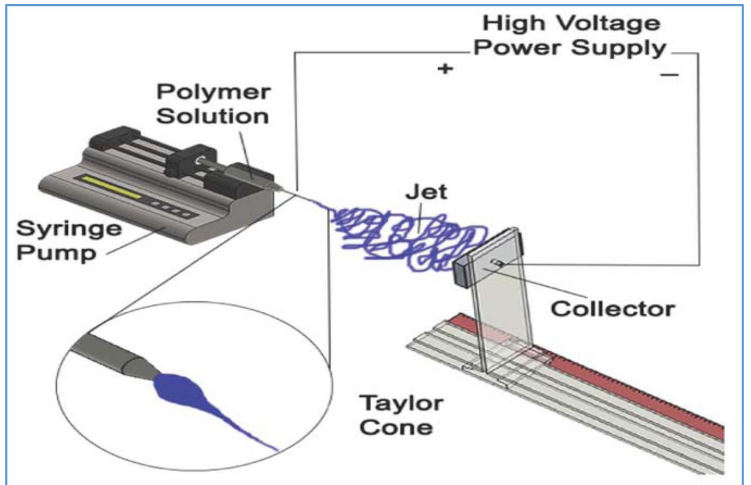

Fig. 1. Electrospinning apparatus and its working principle.

dimethylformamide at various volumetric ratios. The PCS spun fibers were cured in a vacuum chamber in the presence of iodine vapor. Curing was carried out at $180^{\circ} \mathrm{C}$ for $2 \mathrm{~h}$ in a low-pressure curing chamber. Then, the cured fibers were pyrolized at $1300^{\circ} \mathrm{C}$ for $2 \mathrm{~h}$ in a graphite furnace under an argon atmosphere (Fig. 2). ${ }^{6,7)}$

\subsection{Measurements}

The softening and melting points of the PCS precursor were measured with a melting point instrument digital apparatus (IA9100, Bibby Scientific Co. Ltd., USA). The average molecular weight was determined by using a gel permeation chromatography system equipped with a Waters

Table 1. Characteristics of As-Received PCS Precursors

\begin{tabular}{cccccrr}
\hline Contents & $\begin{array}{c}\text { Softening point } \\
\left({ }^{\circ} \mathrm{C}\right)\end{array}$ & $\begin{array}{c}\text { Melting point } \\
\left({ }^{\circ} \mathrm{C}\right)\end{array}$ & $\begin{array}{c}\text { Mw } \\
(\text { Dalton})\end{array}$ & $\begin{array}{c}\text { Mn } \\
(\text { Dalton })\end{array}$ & Polydispersity & Company \\
\hline PCS1609-B & 168 & 185 & 3053 & 1257 & 2.42 & TBM tech. \\
\hline
\end{tabular}

Mw- Weight average molecular weight

Mn- Number average molecular weight
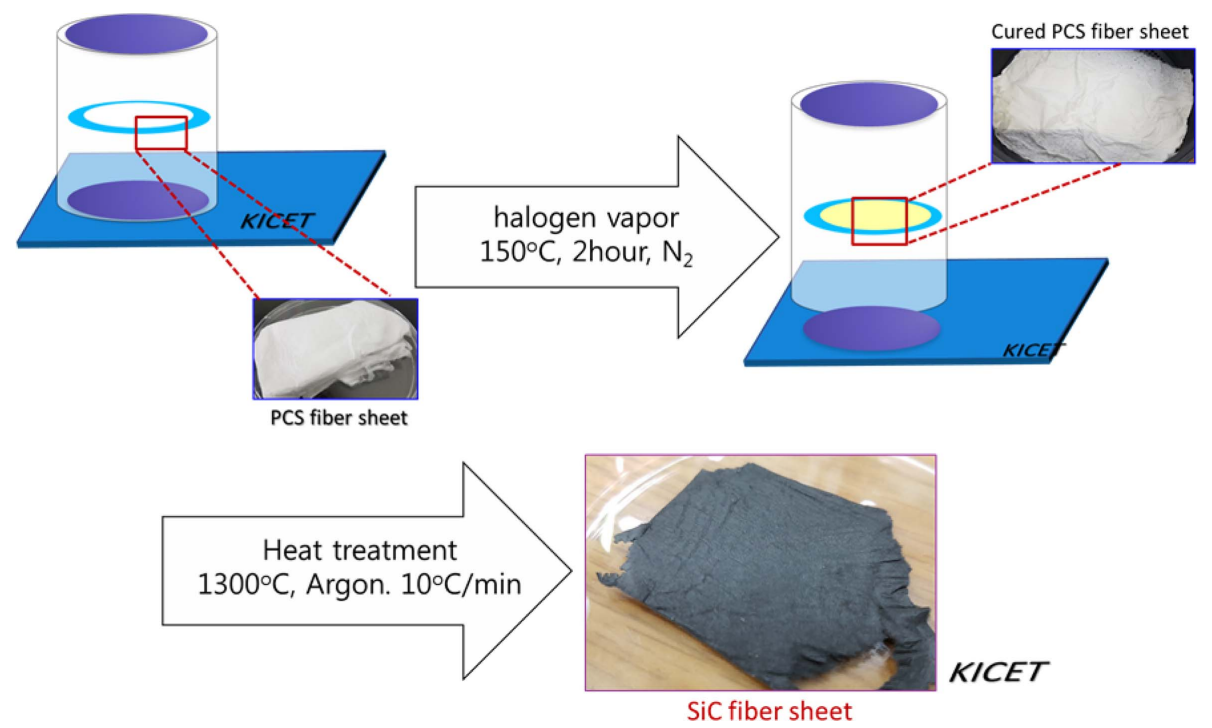

Fig. 2. Fabrication routes of $\mathrm{SiC}$ fiber sheets. 


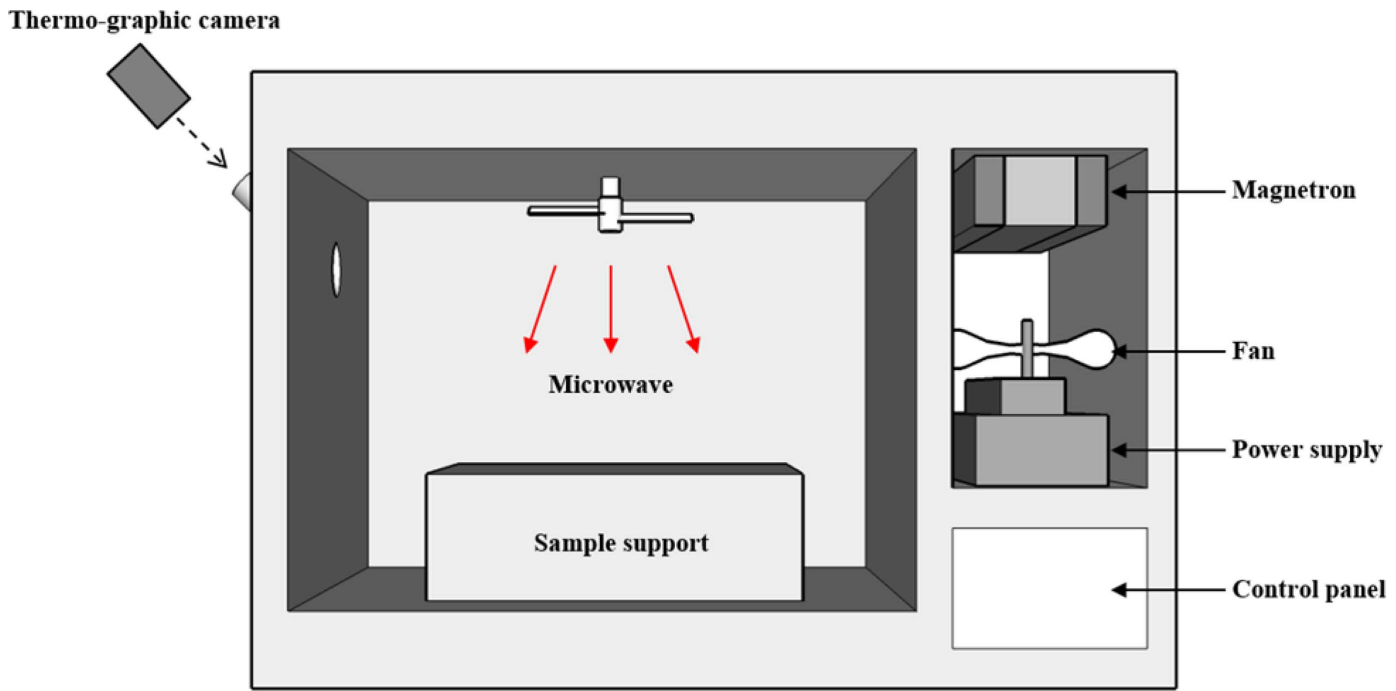

Fig. 3. Microwave irradiation chamber with IR camera thermal measurement.

515 HPLC pump and a Waters 2414 refractive index detector. Toluene was used as a solvent, and the flow rate was 1 $\mathrm{mL} / \mathrm{min}$. Calibration was performed using polystyrene standards.

The chemical structures of the original PCS precursor and the cured fibers were measured by Fourier transform infrared spectroscopy (FT-IR) (FT/IR-4100, JASCO, Japan). Morphological analysis of the original precursor as well as the cured SiC fibers performed by field emission scanning electron microscopy (FE-SEM) (JSM-7610F, JEOL, Japan). Simultaneous thermogravimetric-differential thermal analysis was employed to determine the ceramic yields of the starting material and the cured fibers at $1000^{\circ} \mathrm{C}$ with a $10^{\circ} \mathrm{C} / \mathrm{min}$ heating rate under an $\mathrm{N}_{2}$ atmosphere (DTG- $60 \mathrm{H}$, Shimadzu, Japan). The degree of crystallization of the experimental products was measured by XRD (DMAX 2500, Rigaku, Japan).

\subsection{Microwave irradiation of SiC fiber}

Initially, two types of microwave equipment (turn plate and stirrer) were used in experiments to analyze the interaction between microwave radiation and $\mathrm{SiC}$ fiber. In the case of the turntable microwave, there were some difficulties in measuring the maximum interaction temperature due to the movement of the turntable. Hence, the SiC fiber mats showed different maximum interaction temperatures depending on the plate position. Therefore, we needed to use a stirrer-type of microwave oven rather than the turntable-type microwave. As a result, the $\mathrm{SiC}$ fiber could absorb microwaves equally at every inch of the oven plate (Fig. 3). The microwave oven was constructed with a $1.32 \mathrm{~kW}$ power magnetron in a chamber measuring (W) $500 \mathrm{~mm} \times$ (D) 450 $\mathrm{mm} \times(\mathrm{H}) 400 \mathrm{~mm}$. The heat radiation behavior of the fabricated $\mathrm{SiC}$ fiber mats under microwave radiation were analyzed by infrared thermal imaging (SDS HotFind DXS).

\section{Results and Discussion}

Figure 4(a) shows an SEM image of the heat-treated fibrous mats obtained from $0.9 \mathrm{~g} / \mathrm{mL}$ of PCS solution in a mixture of toluene and dimethylformamide (DMF) (70\% : $30 \%)$. As seen in the image, $\mathrm{SiC}$ fibers emerged with large particles or beads, and this confirms that the spun fiber sheets did not produce completely in this condition. The

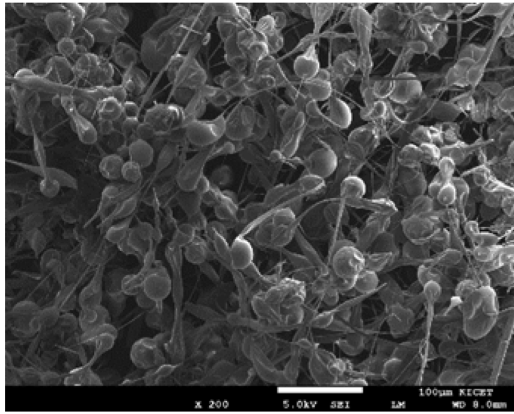

(a)

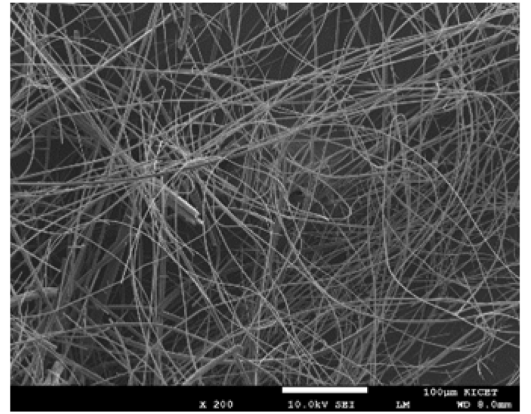

(b)

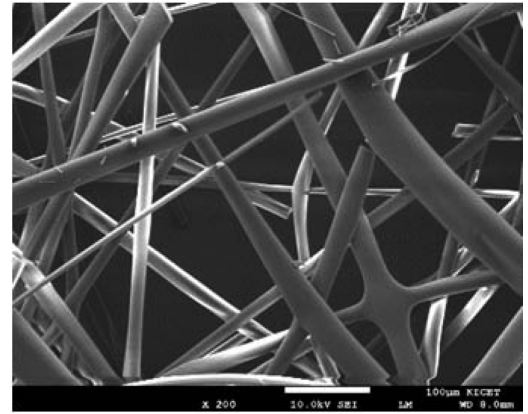

(c)

Fig. 4. SEM images of fabricated PCS and SiC fiber mats, (a) $0.9 \mathrm{~g} / \mathrm{mL}$, (b) $1.1 \mathrm{~g} / \mathrm{mL}$, (c) $1.4 \mathrm{~g} / \mathrm{mL}$ with $3: 7$ (DMF : Toluene). 
electrospinning parameters were changed several times to reduce the number of particles in the sheets. However, all of the fiber mats contained a certain level of particles, even under different spinning conditions.

On the other hand, Fig. 4(b) shows the results obtained from $1.1 \mathrm{~g} / \mathrm{mL}$ of PCS solution; uniform SiC fibers were produced without the appearance of any particles or beads. Thus, we concluded that we could control the fiber shape and size by varying the spinning parameters.

The obtained polycarbosilane fiber mats were examined by FT-IR analysis in the range of $400-4000 \mathrm{~cm}^{-1}$, and the results showed that low-pressure curing of polycarbosilane fibers with iodine has a clear potential for cross-linking in polycarbosilane (Fig. 5). Iodine clearly played an important role for cross-linking of polycarbosilane precursor fibers under low-pressure.

The FT-IR analysis also showed that Si-H stretching $\left(2100 \mathrm{~cm}^{-1}\right)$ peaks decreased, while enhancement of $\mathrm{Si}-\mathrm{CH}_{2}$ Si stretching $\left(1020 \mathrm{~cm}^{-1}\right.$ and $\left.1355 \mathrm{~cm}^{-1}\right)$ peaks could be observed as a result of the curing process. In particular, the degree of C-H cleavage was higher than that of Si-H cleavage with reduced pressure for iodine vapor curing. However, $\mathrm{C}=\mathrm{C}$ bonds $\left(1540 \mathrm{~cm}^{-1}\right.$ and $\left.1630 \mathrm{~cm}^{-1}\right)$ appeared in the cured PCS fiber. This confirmed that the all C-H cleavage did not lead to the development of $\mathrm{C}=\mathrm{C}$ bonds at the early stage of curing under lower pressure. The softening and melting points of PCS are related to increased peaks, such as those of $\mathrm{Si}-\mathrm{CH}_{2}-\mathrm{Si}$ and $\mathrm{Si}-\mathrm{CH}_{3}$ stretching. ${ }^{12)}$

Generally, iodine plays a key role in the breaking of Si-H and $\mathrm{C}-\mathrm{H}$ bonds and induces the development of Si-C-Si linkage in curing products. However, O-H stretching in $\mathrm{Si}-\mathrm{OH}$ and $\mathrm{H}_{2} \mathrm{O}\left(3460 \mathrm{~cm}^{-1}\right.$ and $\left.3680 \mathrm{~cm}^{-1}\right)$ newly appeared, according to the FT-IR analysis results, and this is strongly related to the absorption behavior between iodine and water.

Ly et al. suggested that the formation of water, indicated

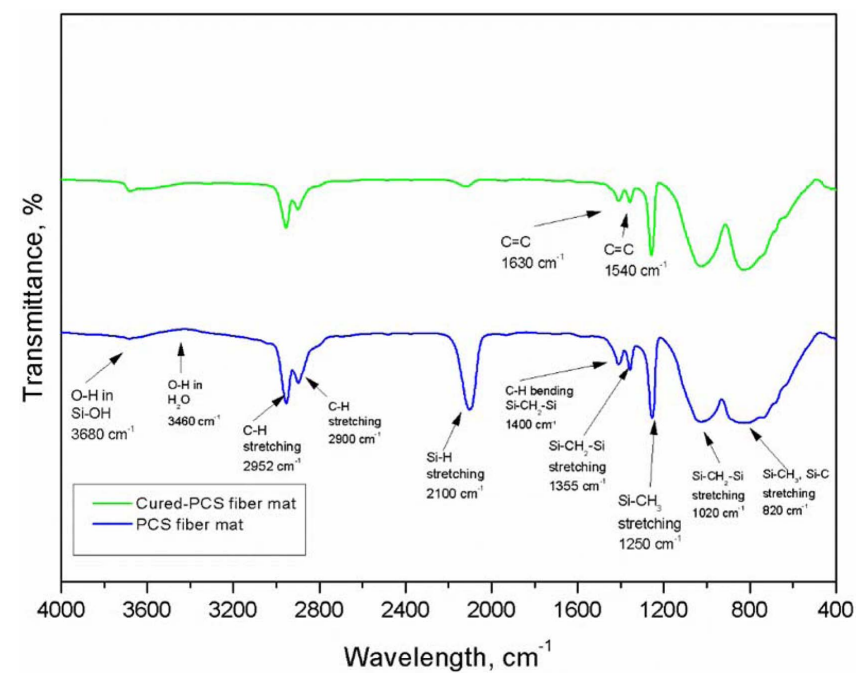

Fig. 5. FT-IR spectra of as-received PCS, PCS fibers cured at reduced pressure. by the appearance of the band at $3460 \mathrm{~cm}^{-1}$, could be due to the following reaction ${ }^{15)}$ :

$$
2 \mathrm{Si}-\mathrm{H}+\mathrm{O}_{2} \rightarrow 2 \mathrm{Si}-\mathrm{OH} \rightarrow \mathrm{Si}-\mathrm{O}-\mathrm{Si}+\mathrm{H}_{2} \mathrm{O} .
$$

However, this reaction could not have occurred in the cured fiber since we conducted the curing under low pressure. Since iodine is the main component of the cured fiber surface, it could easily absorb water from the air in a short period of time. Therefore, a very short time is needed to transfer a cured sample from the curing chamber to the heat-treatment furnace. Also, water molecules could be introduced into the cured fiber during sample preparation for analysis.

Figure 6 presents the thermogravimetric analysis results for the as-received PCS and the cured PCS fibers. The ceramic yield of the cured fiber mat increased significantly compared to the as-received PCS precursor. As seen in Fig. 6, the weight of the as-received PCS fiber started to decrease at $250^{\circ} \mathrm{C}$. This may be related to toluene, which is carried into the PCS precursor during its synthesis process. Overall, the weight loss appeared gradually with increasing temperature in the iodine-vapor-cured fiber mat. Since all the cured fibers contained more than $10 \%$ of iodine content, the application of volatile iodine evaporation would affect the final ceramic yield of the PCS fiber mat.

However, the increase of ceramic yield through iodine vapor curing was obtained from the cured samples. The weight loss difference between the as-received and iodinevapor-cured PCSs was around $24 \%$. As mentioned regarding the FT-IR results, the cleavage of $\mathrm{C}-\mathrm{H}$ and Si-H stretching increased with decreasing curing pressure, which led to cross-linking in the PCS fiber mats. This phenomenon was confirmed by the thermogravimetry analysis (TG) results, which showed increased ceramic yield after the curing process.

The X-ray diffraction patterns of the obtained SiC fiber mats in Fig. 7 indicate the amorphous nature of $\beta$-SiC phase due to relatively broad peaks compared to the standard XRD pattern. The obtained SiC fiber mats showed similar

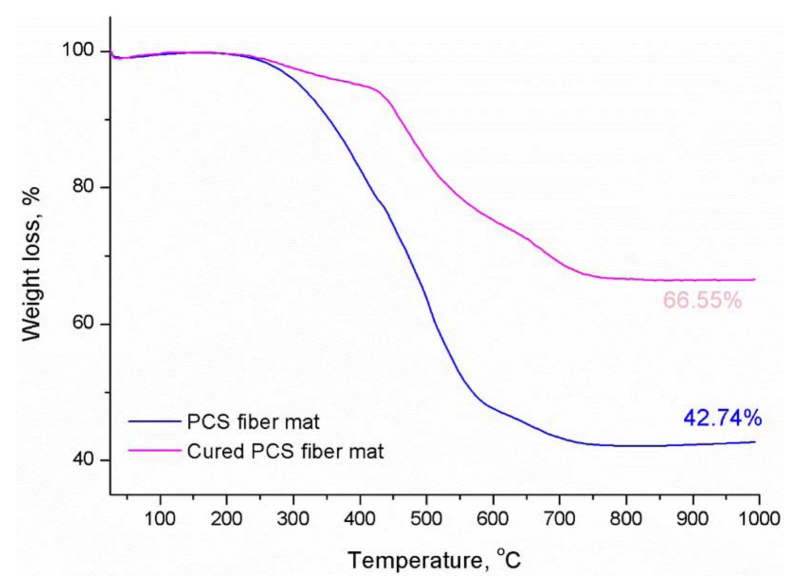

Fig. 6. TG analysis of cured and un-cured PCS depend on electrospinning solution. 


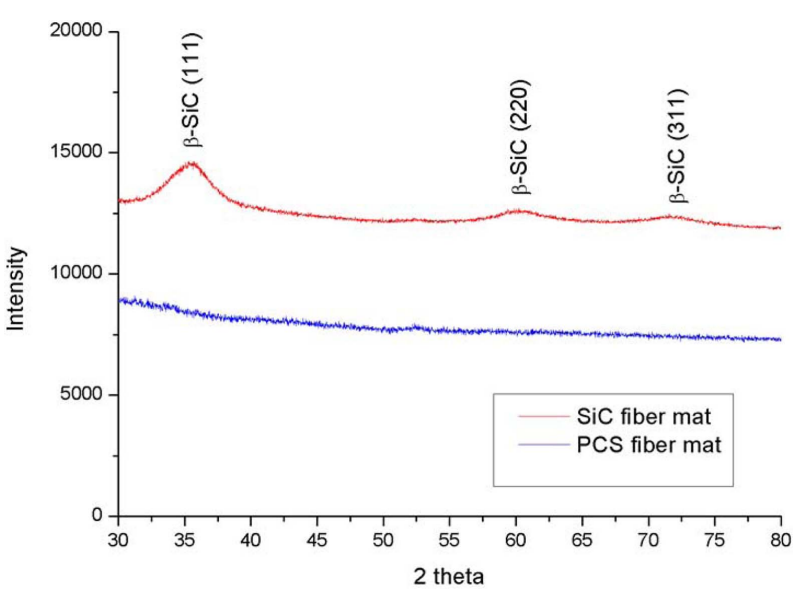

Fig. 7. XRD pattern of PCS and SiC fiber sheets by electrospinning.

peaks, which were assigned to the (111) $\left(2 \theta=35.7^{\circ} ; \mathrm{d}=\right.$ $0.251 \mathrm{~nm}),(220)\left(2 \theta=60^{\circ} ; 2 \mathrm{~d}=0.154 \mathrm{~nm}\right)$, and (311) $(2 \theta=$ $72^{\mathrm{o}} ; 2 \mathrm{~d}=0.131 \mathrm{~nm}$ ) planes. ${ }^{16,17)}$ The three main peaks sharpened with the curing process, which indicates that the degree of crystallization of $\beta$-SiC was higher in the iodinevapor-cured PCS fiber.

Figure 8 shows the SEM analysis results of fabricated SiC fiber mats with a thickness of $0.44 \mathrm{~mm}$. The $\mathrm{SiC}$ fiber mat was derived from a PCS solution (PCS $1.1 \mathrm{~g} / \mathrm{mL}, 3$ : 7-DMF : Toluene in Table 2). Fig. 7 indicates that a flexible paperlike $\mathrm{SiC}$ fiber mat was fabricated successfully by the electrospinning method. The $\mathrm{SiC}$ fiber mat was arranged randomly and the individual fibers had very thin diameters in the range of $2-5 \mu \mathrm{m}$. In the case of heat radiation under the microwave exposure, the $\mathrm{SiC}$ fiber mat with a thickness of $0.44 \mathrm{~mm}$ was irradiated up to $1148^{\circ} \mathrm{C}$.

Beyond the penetration depth, $\mathrm{SiC}$ fiber cannot radiate heat under microwave due to its small diameter for penetration depth. Therefore, the SiC fiber cannot fully absorb the microwave radiation into its body of small diameter. However, the SiC fiber mats fabricated by electrospinning have a random and isotropic structure that can intensify the microwave absorption of $\mathrm{SiC}$ fiber. Thus, in the fabricated mats, the absorbed microwave was easily convertedinto heat by dielectric vibration and eddy currents. As a result, the $\mathrm{SiC}$ fiber mat with a thickness of 0.44 could be radiated up to $1148^{\circ} \mathrm{C}$ under microwave radiation despite its small thickness.

Figure 9 shows the IR-thermal analysis results of the fabricated $\mathrm{SiC}$ fiber mats as a function of their thickness. The thicknesses of SiC fiber mats were (a) $0.44 \mathrm{~mm}$, (b) 0.88 $\mathrm{mm}$, (c) $1.44 \mathrm{~mm}$, (d) $2.14 \mathrm{~mm}$, and (e) $4.43 \mathrm{~mm}$. The $\mathrm{SiC}$
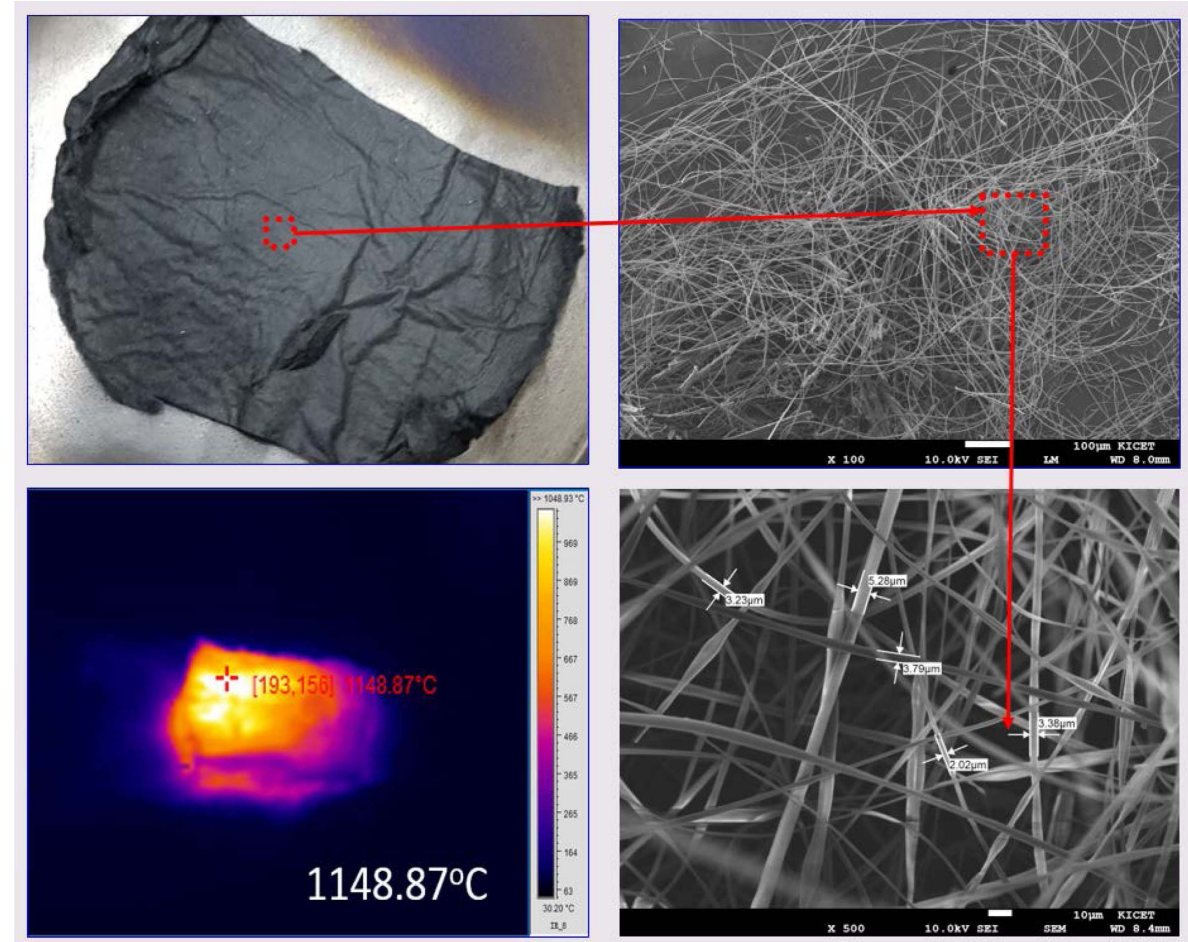

Fig. 8. SEM and IR-thermal analysis of fabricated SiC fiber mats.

Table 2. Spinning Solution Concentration Effects on the Spinnability of Polycarbosilane Precursor

\begin{tabular}{cccccccc}
\hline Solution & $0.9 \mathrm{~g} / \mathrm{mL}$ & $1.0 \mathrm{~g} / \mathrm{mL}$ & $1.1 \mathrm{~g} / \mathrm{mL}$ & $1.2 \mathrm{~g} / \mathrm{mL}$ & $1.3 \mathrm{~g} / \mathrm{mL}$ & $1.4 \mathrm{~g} / \mathrm{mL}$ & $1.5 \mathrm{~g} / \mathrm{mL}$ \\
\hline $3: 7$ & bead & bead & fiber & fiber & \multirow{2}{*}{ Unspinable } & \multirow{2}{*}{ Unspinable } & Unspinable \\
\hline
\end{tabular}




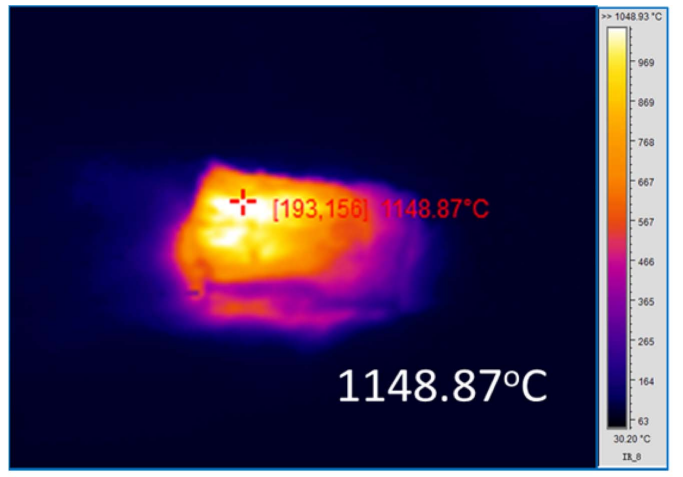

(a) $0.44 \mathrm{~mm}$

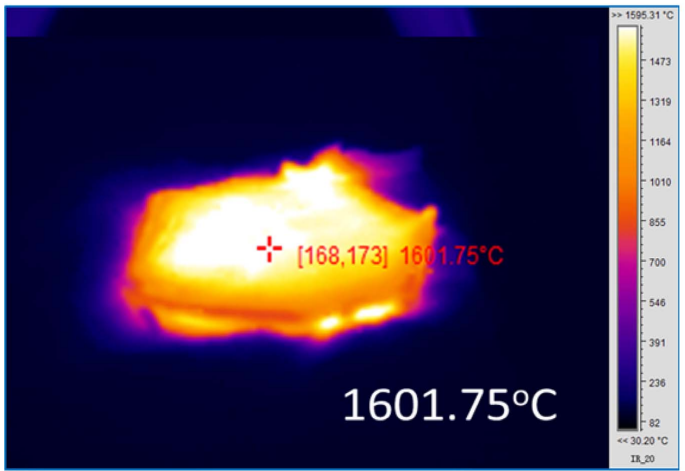

(c) $1.44 \mathrm{~mm}$

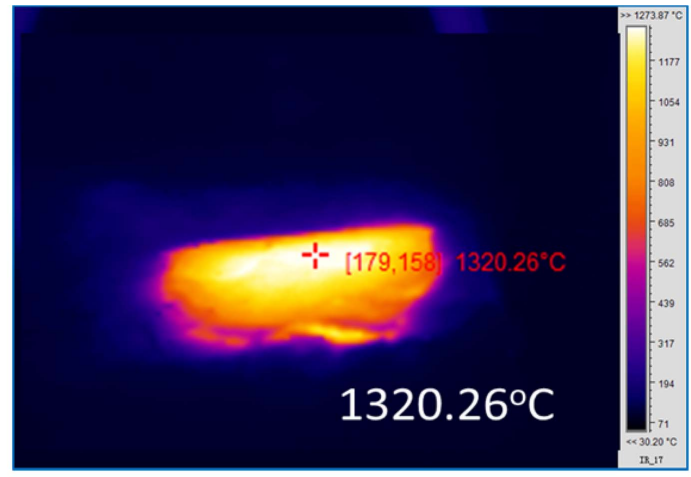

(b) $0.88 \mathrm{~mm}$

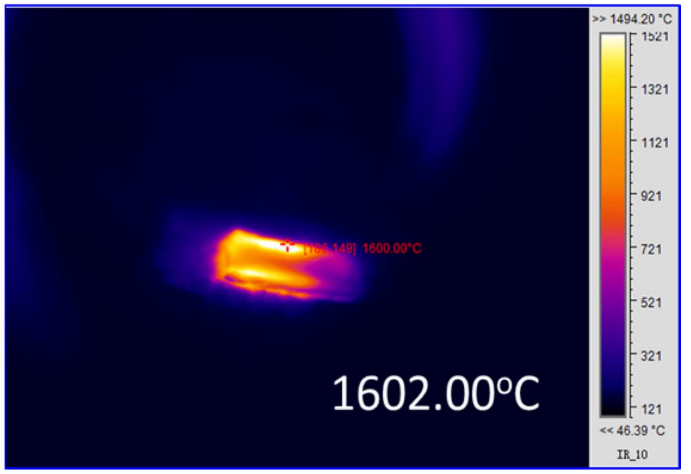

(d) $2.14 \mathrm{~mm}$

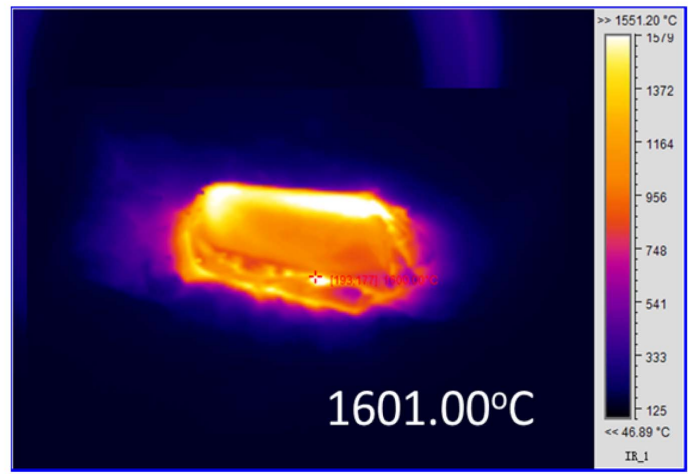

(d) $4.43 \mathrm{~mm}$

Fig. 9. IR-camera images of fabricated $\mathrm{SiC}$ fiber mats as a function of depth of $\mathrm{SiC}$ fiber mats. (a) $0.44 \mathrm{~mm}$, (b) $0.88 \mathrm{~mm}$, (c) 1.44 $\mathrm{mm}$, (d) $2.14 \mathrm{~mm}$, (e) $4.43 \mathrm{~mm}$.

fiber mats were subjected to microwave radiation $(2.45$ $\mathrm{GHz}$ ) and heated up to (a) $1148^{\circ} \mathrm{C}$, (b) $1320^{\circ} \mathrm{C}$, (c) $1601^{\circ} \mathrm{C}$, (d) $1602^{\circ} \mathrm{C}$ and (e) $1601^{\circ} \mathrm{C}$, respectively. This demonstrates a relationship between the thicknesses of the SiC fiber mats and their radiation values, which proportional for this experimental condition. This suggests that the quantity of microwave absorption into the $\mathrm{SiC}$ fiber mats increased with their increasing thickness and density. Chu et al. suggested that microwave absorption increases with multiple layers because both the real and imaginary parts of permittivity increase with higher volume content. ${ }^{3)}$ However, the radiation temperature remained constant at $1600^{\circ} \mathrm{C}$ for the $\mathrm{SiC}$ fiber mats with thicknesses greater than $1.44 \mathrm{~mm}$.
Hence, this indicates that saturation of microwave absorption can be achieved by fabricating mats with a certain thickness. Consequently, it is confirmed that the random and isotropic microstructure of the $\mathrm{SiC}$ fiber mats can increase the microwave absorption of $\mathrm{SiC}$ fiber mats with the optimal thickness.

\section{Conclusions}

High-performance silicon carbide fiber mats were successfully obtained from a PCS precursor by electrospinning and low-pressure curing in the presence of iodine vapor. The $\mathrm{SiC}$ fiber mats showed high heat radiation under microwave 
radiation. The $\mathrm{SiC}$ fiber mat thickness was found to play an important role for heat radiation due to the improvement of microwave absorption. It was confirmed that the random and isotropic microstructure of $\mathrm{SiC}$ fiber mat increased the microwave absorption capacity of the $\mathrm{SiC}$ fiber mats. However, above a specific SiC fiber mat thickness, the heat radiation is remained constant because the microwave absorption into the $\mathrm{SiC}$ fiber mat was not increased. This is related to the penetration depth of microwaves into the $\mathrm{SiC}$ fiber mat, and the saturation of microwave absorption can be achieved at the optimal thickness.

\section{REFERENCES}

1. S. Yajima, J. Hayashi, J. Omori, and K. Okamura, "Development of a Silicon Carbide Fibre with High Tensile Strength," Nature, 261 [5562] 683-85 (1976).

2. R. Warren and C. H. Anderson, "Silicon Carbide Fibres and Their Potential to Use in Composite Materials. Part II," Composites, 15 [2] 101-11 (1984).

3. Z. Chu, H. Cheng, Y. Zhou, Q. Wang, and J. Wang, "Anisotropic Microwave Absorbing Properties of Oriented SiC Short Fiber Sheet," Mater. Des., 31 [6] 3140-45 (2010).

4. S. R. Levine, E. J. Opila, M. C. Haibig, J. D. Kiser, M. Singh, and J. A. Salem, "Evaluation of Ultra-High Temperature Ceramics for Aeropropulsion Use," J. Eur. Ceram. Soc., 22 [14-15] 2757-67 (2002).

5. X. G. Liu, Y. D. Wang, L. Wang, J. G. Xue, and X. Y. Lan, "Preparation and Microwave Electromagnetic Properties of Cross Shaped SiC Fibers," J. Inorg. Mater., 25 [4] 44144 (2010).

6. K.-E. Khishigbayar, J. M. Seo, and K. Y. Cho, "Heating Behavior of Silicon Carbide Fiber Mat under Microwave," J. Korean. Ceram. Soc., 53 [6] 707-11 (2016).

7. J. Hong, K. Y. Cho, D.-G. Shin, J.-I. Kim, S. T. Oh, and D. H. Riu, "Low-Temperature Chemical Vapour Curing Using Iodine for Fabrication of Continuous Silicon Carbide Fibres from Low-Molecular-Weight Polycarbosilane," J. Mater. Chem. A, 2 [8] 2781-93 (2014).
8. D. G. Shin, K. Y. Cho, E. J. Jin, and D. H. Riu, "Processes and Applications of Silicon Carbide Nanocomposite Fibers"; pp.55-59 in IOP Conference Series: Materials Science and Engineering 18 (SYMPOSIUM 5). Osaka, Japan, 2011.

9. D. G. Shin, Y. J. Lee, E. J. Jin, K. Y. Cho, Y. Kim, S. R. Kim, W. T. Kwon, J. S. Hong, and D. H. Riu, "Microstructure and Properties of Web-Type Polycrystalline SiC Fiber Prepared by Electrospinning and Sintering of Aluminum Doped Polycarbosilane," J. Ceram. Process. Res., 15 [5] 298-304 (2014).

10. H. Wu, W. Pan, D. Lin, and H. Li, "Electrospinning of Ceramic Nanofibers: Fabrication, Assembly and Applications," J. Adv. Ceram., 1 [1] 2-23 (2012).

11. B. M. Eick and J. P. Youngblood, "SiC Nanofibers by Pyrolysis of Electrospun Preceramic Polymers," J. Mater. Sci., 44 [1] 160-65 (2009).

12. B. Wang, Y. Wang, Y. Lei, N. Wu, Y. Gou, C. Han, and D. Fang, 'Hierarchically Porous SiC Ultrathin Fibers Mat with Enhanced Mass Transport, Amphipathic Property and High-Temperature Erosion Resistance," J. Mater. Chem. A, 2 [48] 20873-81 (2014).

13. Y. Yu, Y. Chen, and L. An, "Flexible Hydrophobic and Lipophilic Aluminum-Doped Silicon Carbide Fibrous Mats Synthesized by Electrospinning Polyaluminocarbosilane," Int. J. Appl. Ceram. Technol., 11 [4] 699-705 (2014).

14. S. H. Choi, D. Y. Youn, S. M. Jo, S. G. Oh, and I. D. Kim, "Micelle-Mediated Synthesis of Single-Crystalline B(3C)SiC Fibers via Emulsion Electrospinning," ACS Appl. Mater. Interfaces, 3 [5] 1385-89 (2011)

15. H. Q. Ly, R. Taylor, R. J. Day, and F. Heatley, "Conversion of Polycarbosilane (PCS) to SiC-Based Ceramic: Part 1. Characterisation of PCS and Curing Products," J. Mater. Sci., 36 [16] 4037-43 (2001).

16. H. Hou, F. Gao, G. Wei, M. Wang, J. Zheng, B. Tang, and W. Yang, "Electrospinning $3 \mathrm{C}$-SiC Mesoporous Fibers with High Purities and Well-Controlled Structures," Cryst. Growth. Des., 12 [1] 536-39 (2012).

17. H. A. Liu and K. J. Balkus Jr., "Electrospinning of Beta Silicon Carbide Nanofibers," Mater. Lett., 63 [27] 2361-64 (2009) 